\title{
REDUCTION OF VOLTAGE STRESS AND INRUSH CURRENT OF POWER TRANSFORMERS USING CONTROLLED SWITCHING
}

\author{
Andreas EBNER \\ High Voltage Laboratory, Swiss Federal Institute of Technology Zurich - Switzerland \\ aebner@eeh.ee.ethz.ch
}

\begin{abstract}
Random energisation of power transformers often causes significant inrush currents and steep switching voltage wave fronts that are responsible for several adverse effects like huge current forces in the transformer windings, dielectric stress of the transformer winding insulation and temporary overvoltages. Controlled switching taking into account the residual flux is able to eliminate these inrush currents, but significant voltage wave fronts emerge from the switching action in almost all cases. Thus, a new algorithm is presented that extends the existing one so that a combined reduction of all stresses can be achieved. Systematic energisation studies were carried out in EMTPATP to calculate the optimal closing times of a three-legged $400 \mathrm{kVA}$ transformer. Thereby, an inrush current peak of $1 \mathrm{pu}$ will be tolerated so that the voltage wave front amplitude can be reduced. Depending on the strategy for controlled switching, the maximum voltage wave front amplitude of all phases can be limited to $0.75 \mathrm{pu}$ ("Delayed Closing”, reduction of $11.7 \%$ ) respectively to $0.7 \mathrm{pu}$ for "Rapid Closing” (reduction of $22 \%$ ).
\end{abstract}

\section{INTRODUCTION}

Transient inrush currents appear during the energisation of power transformers and can exceed many times its rated current. In worst case their peak values are in the same region as the short-circuit current of the transformer and the transients reach the steady-state magnetising current only after a few seconds while in best case no inrush currents emerge at all. Thereby, the peak value of the inrush current not only depends on the switching instant but also on the residual flux value and on the saturation characteristic of the transformer core.

With typical residual fluxes up to $0.85 \mathrm{pu}$ and worst-case switching instant the magnetic flux reaches a maximum value of $2.85 \mathrm{pu}([1])$. This is far above the saturation point of the core magnetisation characteristic (typically in the region of $1.125-1.25 \mathrm{pu}$, [2]) and therefore, the core will completely be driven into saturation which leads to high inrush currents.

Another phenomenon that occurs during the energisation of any element is the switching impulse. Due to the breakdown of the dielectric gap between circuit-breaker contacts during closing operation, a prestrike occurs. This results in a switching impulse whose voltage wave front enters the element to be switched and dielectrically stresses it.

\section{EFFECTS OF TRANSIENTS DURING ENERGISATION}

Several undesired effects occur due to the inrush currents and their harmonics ([3]) as well as due to the voltage wave fronts that affect the transformer, the grid and the network protection schemes (false tripping of protective relays).

\section{Current Forces in the Transformer Windings}

Inrush currents cause high mechanical current forces in the transformer windings that possibly reduce its lifecycle. A frequent reason for failures is the wear of insulation due to vibrations that significantly occur at high currents, e.g. inrush currents.

Normally, the forces that occur during short-circuit are used to dimension the mechanical strength of the insulation. Steurer and Fröhlich compared the electro-dynamic forces in the windings during short-circuit and inrush and showed that they are in the same region ([4]). While a short-circuit current is interrupted after some tens of ms, inrush currents are weakly damped and can last for some seconds which results in much longer vibrations. Thus, frequent no-load energisation of power transformers leads to a higher potential of permanent mechanical damage of the winding insulation and thus to a higher risk of premature failures.

\section{Dielectric Stress of Transformer Insulation}

Especially with $\mathrm{SF}_{6}$ and vacuum circuit-breakers, uncontrolled switching is a potential source of very fast transients ([5]). Due to their cumulative effect on the dielectric ageing of the transformer winding insulation, these transients may be responsible for premature failures. Several utilities reported much higher failure rates of UHV transformers and high failure rates shortly after installation without occurrence of a lightning or short-circuit event ([6], [7]). Most likely, these failures result from dielectric failure mechanisms that emerge from internal voltage oscillations between individual windings. These oscillations are excited by switching transients (voltage wave fronts) and thus, multiple transformer energisation has a significant effect on the appearance of failures as could be shown in [5].

\section{Temporary Overvoltages (TOVs)}

In several cases severe TOVs were measured during the energisation of transformers ([8] - [11]). On the high voltage level, TOVs typically arise in systems with weak damping and relatively large capacitances.

Together with the transformer inductance, this capacitance 
forms a weakly damped, low-frequency oscillating circuit. If its natural frequency corresponds to a harmonic of the inrush current (typically $2^{\text {nd }}$ to $5^{\text {th }}$ ) and its amplitude is big enough, the oscillating circuit will be excited permanently. This causes TOVs in the range of $1.5-2.0$ pu with duration of some 100 periods. Thus, TOVs not only stress the transformer insulation but also the surge arresters that can be thermally destroyed due to repetitive actuation.

\section{PURPOSE OF THE NEW STRATEGY}

To date, controlled switching taking into account the residual flux is the most promising method to reduce the adverse effects during transformer energisation ([1]). This strategy completely eliminates the inrush currents whereby current forces in the transformer windings and TOVs are avoided. Unfortunately, no active control of the voltage wave front amplitude is possible with this algorithm and almost all residual flux patterns cause significant voltage wave fronts that lead to dielectric stress in the transformer winding insulation.

Nevertheless, a specific reduction of the voltage wave front amplitude is desirable to reduce the dielectric stress in the transformer coil. This has to be achieved by tolerating a moderate inrush current. If the amplitude of the inrush current is small, no significant current forces will arise; furthermore the amplitudes of the harmonics will be too little to excite TOVs. Thus, an inrush current of 1 pu can be tolerated to obtain the necessary degree of freedom for reducing the amplitude of the voltage wave front without generating noteworthy stresses because of inrush currents (current forces, TOVs).

Based on this knowledge, the algorithm of Brunke and Fröhlich ([1]) was modified so that a combined reduction of all stresses due to inrush current and voltage wave front can be achieved. The proposed algorithm reduces the amplitude of the voltage wave front by tolerating a maximum inrush current peak of 1 pu.

\section{SIMULATION SETUP}

The new strategy is used with transformers of the power transmission level. Ref. [12] and [13] showed that these transformers are typically built as separate winding transformers with a three-legged stacked core. At least one winding is star-connected and it is assumed that the transformer is energised from this side at no-load operation.

Therefore, systematic energisation studies were carried out using a three-legged $400 \mathrm{kVA}$ dry-type distribution transformer whose construction data was available and whose properties are similar to the ones of the transformers on the transmission level (Table 1). The transformer was modelled in EMTP-ATP using the principle of duality and type-96 elements to properly represent the magnetic behaviour of the iron core. Besides a correct representation of the magnetic coupling in the core, the leakage inductance significantly influences the performance of the model. To parameterise the transformer model extended test data as well as construction data were used.
Table 1. Transformer Data

\begin{tabular}{|c|c|c|c|}
\hline \multicolumn{4}{|l|}{ Rated values } \\
\hline Power & $\mathrm{S}_{\mathrm{R}}$ & 400 & $\mathrm{kVA}$ \\
\hline Voltage & $\mathrm{U}_{\mathrm{R}}$ & $16.8 / 0.42$ & $\mathrm{kV}$ \\
\hline Current & $\mathrm{I}_{\mathrm{R}}$ & $13.75 / 550$ & $\mathrm{~A}$ \\
\hline Vector group & & \multicolumn{2}{|l|}{ Dyn5 } \\
\hline Core type & & \multicolumn{2}{|l|}{ three-legged } \\
\hline \multicolumn{4}{|c|}{ No-load test data (low voltage side) } \\
\hline Current & $\mathrm{I}_{0}$ & 0.282 & $\mathrm{pu}$ \\
\hline Losses & $\mathrm{P}_{0}$ & 912 & $\mathrm{~W}$ \\
\hline \multicolumn{4}{|c|}{ Short-circuit test data (high voltage side) } \\
\hline Short-circuit impedance & $\mathrm{Z}_{\mathrm{SC}}$ & 5.99 & $\mathrm{pu}$ \\
\hline Losses & $\mathrm{P}_{\mathrm{SC}}$ & 6057 & $\mathrm{~W}$ \\
\hline
\end{tabular}

The transformer is connected via ideal circuit-breakers to an ideal voltage source (Figure 1). This represents the worst case scenario because the grid inductance is missing and therefore, the inrush current is solely determined by the properties transformer. For evaluating the results, the currents as well as the voltages across the circuit-breakers are measured.

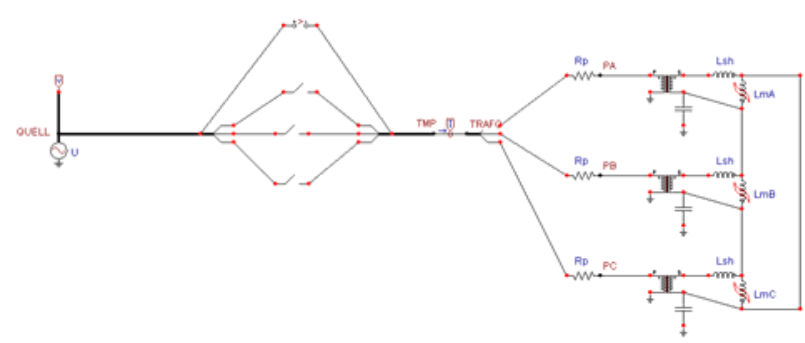

Figure 1. Model for systematic energisation studies

\section{CONTROLLER INTERFACE BETWEEN MATLAB AND EMTP-ATP}

To identify the optimal closing times for a combined reduction of all stresses, systematic energisation studies were carried out for different combinations of closing times and residual flux values. In principle, only one simulation for a specific combination of closing time and residual flux can be done at once in EMTP-ATP. Hence, a controller interface was implemented in MATLAB that systematically varies the parameters (closing time, residual flux) and finally evaluates the simulation results. The interface first updates the input file for the simulation with the actual closing times and residual flux values. Then, it runs the simulation in EMTP-ATP and imports its results into MATLAB. For each simulation and for each phase, the controller module finally evaluates the maximum inrush current value (inrush current peak) and the voltage across the circuit-breaker immediately before it is closed (amplitude of the voltage wave front) and stores these values in a matrix. A more detailed description of the controller interface can be found in [14], chapters IV.A, IV.C and IV.D where similar algorithms were used for systematic inrush current studies in the laboratory. 


\section{RESULTS}

It was assumed, that - independent of the residual flux pattern - the first phase to be energised is always the centre phase of the transformer (phase V). Due to the magnetic coupling in the transformer core, the instant of first phase energisation directly influences the behaviour of second and third phase energisation when the "Rapid Closing" strategy is used. Therefore, the results of first phase energisation will be discussed at first and the results have to be used in the simulations of second and third phase energisation.

\section{Energisation of the first Phase}

Figure 2 shows the results of the systematic energisation study for the first phase. In the upper graph, it can be seen that no inrush currents occur in the region around $0 \mathrm{~ms}$ closing time deviation. This region together with the saturation and the leakage inductance are crucial for the practicability of the new algorithm. If no inrush currents are tolerated, this region is quite narrow whereby no substantial reduction of the voltage wave front amplitude can be achieved. By tolerating an inrush current of $1 \mathrm{pu}$, much wider regions occur where the evaluation script looks for the minimal voltage wave front amplitude. The corresponding closing time deviation relative to the optimal one according to [1] is noted and corresponds to the optimal closing time for a combined reduction of all stresses that occur during transformer energisation.

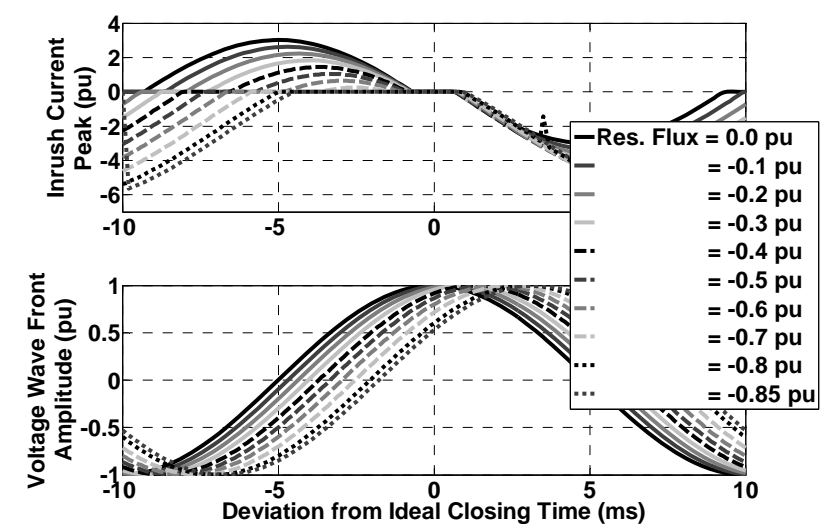

Figure 2. First phase energisation - inrush current peak and voltage wave front amplitude for different closing time deviations relative to the ideal closing time according to [1]

This analysis has to be done for different residual fluxes and the final results are shown in Figure 3. The voltage wave front amplitude can completely be eliminated for high absolute residual flux values ( $>0.51 \mathrm{pu})$. Additionally, the inrush currents can be eliminated for absolute residual fluxes higher than $0.76 \mathrm{pu}$; in this case, the transformer will be energised optimally without any stresses. Unfortunately, these excellent results are only valid for single-phase transformers without interphase coupling. For three-phase transformers, the performance of the other phases has to be taken into account as well.
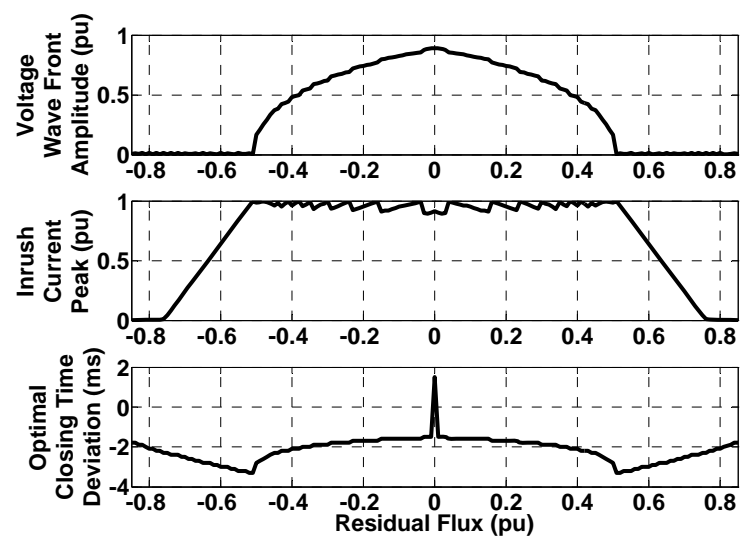

Figure 3. First phase energisation - voltage wave front amplitude, inrush current peak and optimal closing time deviation for different residual fluxes

\section{Energisation of all Phases using "Delayed Closing"}

If "Delayed Closing" is used to energise the second and third phases, the amplitude of the voltage wave fronts can be limited to $0.75 \mathrm{pu}$ for almost all residual flux patterns (Figure 4). For second and third phase, this is a reduction of $11.7 \%$ compared to controlled switching as stated in [1] (voltage wave front amplitude is always $0.867 \mathrm{pu}$ ). The voltage wave front amplitude of the first phase can be completely eliminated for residual flux patterns, where the centre leg residual flux is higher than $0.51 \mathrm{pu}$, whereby the average voltage wave front amplitude can be lowered to $50 \%$. This is the best result than can be achieved using "Delayed Closing".

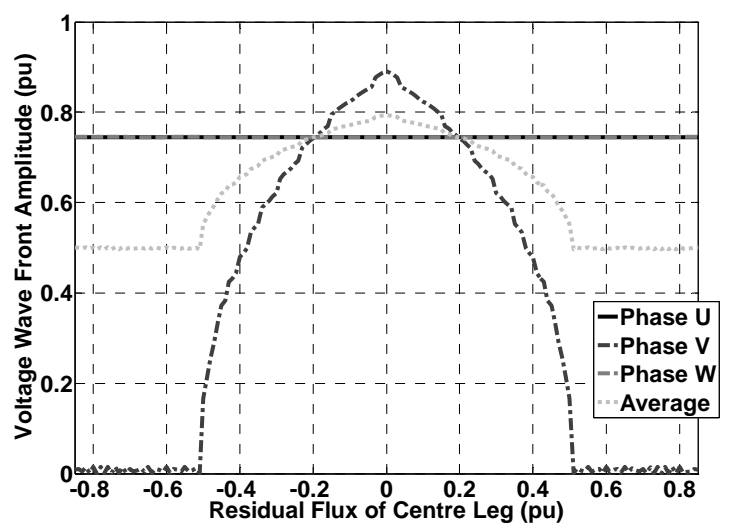

Figure 4: "Delayed Closing" strategy - amplitudes of the voltage wave fronts for different residual flux patterns and inrush current peaks of 1 pu

\section{Energisation of all Phases using "Rapid Closing"}

Due to asymmetric magnetic flux and voltage relations immediately after energisation a completely different graph is created (see Figure 5). The average value of the voltage wave front amplitude can be limited to $50 \%$ in the region [0.63...0.85] pu (residual flux of the centre leg). However, the amplitudes of phases $\mathrm{U}$ and $\mathrm{W}$ amount to $0.75 \mathrm{pu}$ which corresponds to the best result for "Delayed Closing". The most qualified region for "Rapid Closing" is between $-0.82 \mathrm{pu}$ and $-0.6 \mathrm{pu}$ for the centre leg residual flux. 
Therein, the average of the voltage wave front amplitude can be kept below $50 \%$ and the maximum of all phases is $0.7 \mathrm{pu}$. This corresponds to a reduction of $22 \%$ compared to controlled switching according to [1] (amplitude of the voltage wave front is $0.92 \mathrm{pu}$ in worst case).

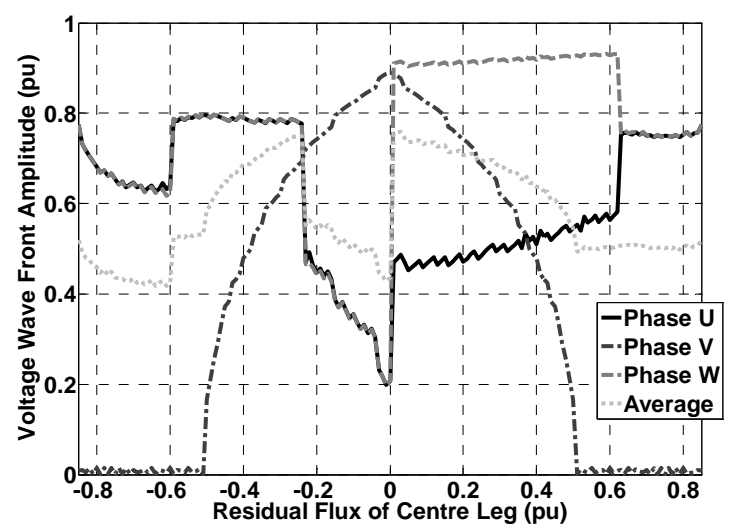

Figure 5. "Rapid Closing" strategy - amplitudes of the voltage wave fronts for different residual flux patterns and inrush current peaks of 1 pu

\section{CONCLUSIONS}

The proposed algorithm can be used to specifically reduce the amplitude of the voltage wave front that emerges from the switching action. It improves the existing algorithm of Brunke and Fröhlich ([1]) so that all stresses that occur during transformer energisation can be reduced. Thereby, a compromise between reducing the voltage wave front amplitude and the amplitude of the inrush current peak has to be found so that all adverse effects during transformer energisation can be significantly reduced respectively eliminated. Nevertheless, a complete elimination of all stresses in each phase is not possible for three-phase transformers that are the most common transformer configurations on the transmission level.

Inrush currents of 1 pu can be tolerated because with this amplitude, neither significant current forces in the transformer windings nor temporary overvoltages will occur. By tolerating inrush currents of $1 \mathrm{pu}$, the amplitude of the voltage wave front can be reduced significantly. Depending on the switching strategy, a reduction of $11.7 \%$ for "Delayed Closing” respectively a reduction of $22 \%$ for "Rapid Closing" can be achieved compared to the values of controlled switching according to [1]. Because these results are solely valid for certain residual flux patterns, this algorithm should be used together with controlled deenergisation by what the residual flux pattern can be set precisely.

\section{REFERENCES}

[1] J.H. Brunke, K. Fröhlich, 2001, "Elimination of Transformer Inrush Currents by Controlled Switching - Part I: Theoretical Considerations", IEEE Trans. on Power Delivery vol. 16 no. 2, 276-280.
[2] A. Ebner, 2008, "Kontrolliertes Einschalten von Leistungstransformatoren - Anforderungen an den Leistungsschalter und die Remanenzflussmessung”, Internal Project Report, High Voltage Laboratory, ETH Zurich.

[3] C.E. Lin, C.L. Cheng, C.L. Huang, J.C. Yeh, 1993, "Investigation of Magnetising Inrush Current in Transformers. Part II - Harmonic Analysis”, IEEE Trans. on Power Delivery vol. 8 no. 1, 255-263.

[4] M. Steurer, K. Fröhlich, 2002, “The Impact of Inrush Currents on the Mechanical Stress of High Voltage Power Transformer Coils”, IEEE Trans. on Power Delivery vol. 17 no. 1, 155-160.

[5] CIGRÉ Joint WG A2-A3-B3.21, 2005, "Electrical Environment of Transformers - Impact of Fast Transients”, Electra no. 218, 25-37.

[6] R. Malewski, J. Douville, L. Lavallée, 1988, "Measurements of Switching Transients in 735-kV Substations and Assessment of their Severity for Transformer Insulation”, IEEE Trans. on Power Delivery vol. 3 no. 4, 1380-1390.

[7] L.B. Wagenaar, J.M. Schneider, J.A. Fleeman, 1994, "EHV Transformer Dielectric Specification Improvements”, IEEE Trans. on Power Delivery vol. 9 no. $1,265-284$.

[8] A. Mercier, E. Portales, Y. Filion, A. Salibi, 2002, "Transformer Controlled Switching taking into Account the Core Residual Flux - A real Case Study”, CIGRÉ Session 2002, no. 13-201.

[9] D. Povh, W. Schultz, 1978, “Analysis of Overvoltages caused by Transformer Magnetizing Inrush Currents”, IEEE Trans. on Power Apparatus and Systems vol. PAS-97 no. 4, 1355-1365.

[10] G. Sybille, M.M. Gavrilovic, J. Bélanger, V.Q. Do, 1985, "Transformer Saturation Effects on EHV System Overvoltages”, IEEE Trans. on Power Apparatus and Systems vol. PAS-104 no. 3, 671-680.

[11] K. Hur, S. Santoso, 2005, “Analysis and Modeling of Dynamic Overvoltage Phenomena due to Transformer Energizing”, IEEE General Meeting 2005, vol. 2, 1126-1130.

[12] E. Colombo, G. Santagostino, 1984, "Results of the Enquiries on actual Network Conditions when Switching Magnetizing and Small Inductive Currents and on Transformer and Shunt Reactor Saturation Characteristics”, Electra no. 94, 35-53.

[13] J. Taylor, D.J. Bornebroek, 1982, “Main Transformer Arrangements and related Matters in Generating Stations”, Electra no. 82, 87-108.

[14] A. Ebner, M. Bösch, R. Cortesi, 2008, “Controlled Switching of Transformers - Effects of Closing Time Scatter and Residual Flux Uncertainty”, $43^{\text {rd }}$ International Universities Power Engineering Conference, UPEC, no. 161. 